\title{
ON THE FUTURE DEVELOPMENT OF SCIENTIFIC EDUCATION IN AMERICA,
}

By S. EnWard Warren, C. E.

Prof. of Deseriptive Geometry, \&c., in the Rensselaer Pol. Inst., Troy, N. Y.

(Continued from Vol. LVI., page 284.)

IN contemplating the total field of study, we make the first and grandest distinction to be that of Creature and Creator, a distinction whose truth is sufficiently testified to by the universality of religion in some form.

The creature, so far as spiritual and uncorrupt, can know the Creator through His works, through its own intuitions, and through such communications as the Author of a spirit can, and, as is most natural to suppose, would make to that spirit.

In limiting ourselves, now, to the created universe, we distinguish, for practical purposes, Man and Nature; or, Man and all else that is created.

Man, being conscious both of self and the world, as separate, can make each an object of study.

Each, considered as free, or as uninterfered with by man, is properly said to be studied by observation.

Each, as conditioned by human interposition, is said to be studied by experiment.

Observation, then, we repeat, is the study of humanly free man and nature.

Experiment is the study of humanly conditioned man or nature.

The results of both observation and experiment, upon both man and nature, may then further be submitted to the exercise of reflec: tion, or may be studied by reflection.

Now, FIRST, in observation of nature, attention is given to the perceptions. In observation of self, attention is given to consciousness. In experiment, the imagination is exercised in devising the conditions to be imposed upon the objects of study. In reflection, the powers of abstraction, judgment and reasoning are exercised upon things seen or remembered, and the processes of comparison, classification, and generalization are conducted. Thus, in observation, experiment and reflection, the whole intellectual being is exercised; and if we include the stimulating motives, and inspiring ends which induce these activities, and remember the body as the instrument

Vol. LVII.-Third ShrIms.-No. 3.-MaRCH, 1869. 
of the spirit, the whole being, without qualification, may be said to be called into action.

SECOND.-Man and nature must be either free or conditioned. There is no third state possible to either.

Therefore, as observation, experiment, and reflection engage the whole being of man upon both himself and Nature, we might conclude that they are the sources of all original human knowledge whatever.

But the guiding distinction at this point is, that Nature and Life are not conditioned by man alone. They are conditioned for man by the Creator, so that the conduct of life presents itself as a series of practical problems for active solution. In other words, in all rational activity, or intelligent practice in the business of life, one is studying, experimentally, the right use of himself under the conditions in which he finds, not puts himself; how to develop and wield his powers and opportunities. But, in this form of experi. ment, the conditions are externally imposed, presented to the man, and not imposed by him. We have, then, an important difference of meaning between the expressions, learning by experiment, and by experience, or practice.

Whence we conclude that a perfectly composed course of study should provide for study by observation, experiment, reflection and practice.

But of these, reflection is chief, so that the results of observation, experiment, and life experience serve to fully develop or educate the man just in proportion as they are made food for reflection.

This fact demonstrates the impossibility of ranging certain studies exclusively under each head, and thus illustrates the principle mentioned before, that things are distinguished not by the exclusive presence of certain attributes, different in each, but by their predominance. Thus, the study of natural history, in its actual specimens, is conspicuously a study by observation. But it is by reflection upon the results of observation, and by repeated experimental attempts, that its objects can be properly classified. And again, all those special forms of a general conclusion in geometry, which result from particular suppositions on the given con. ditions, and which can be determined by inspection, are thereby really learned by observation. Also, it is by reflection upon experiments or experience, that the laws of physics and of animal or rational life are determined. 
The principles just stated explain why it is that any study, thoroughly and fully pursued, can liberally develop the whole man, It is because when, in the familiar expression of feeling, we say a man throws his whole being, or goes with his whole soul, into any pursuit, he also does so literally - that is, he exercises all his powers on such pursuit, and therefore does broadly, generously, and truly educate himself by it. This also explains a former statement, viz., that the mind thrives best on what it constitutionally likes best.

Nevertheless, and especially when the natural bent of a mind is not very strong, and it seeks, accordingly, development by a pre. scribed course, such a course may well be composed of such a selection of subjects, as generally and most readily and obviously tends to cultivate each of the several powers of the mind.

We are now prepared to state the jdea of truly liberal education. It should be one which, at every stage, affords, 1st, opportunity for study by observation, experiment, reflection, practice; and, $2 \mathrm{~d}$, pro. vides various subjects, or exercises, under each head, from which the student can make a selection.

There is, however, an important limitation here to be noted. The world has seen two great civilizations-that is, two which are still visibly operative-the pagan civilization of Greece and Rome, and the modern civilization of the less corrupted portions of Christendom. A large body of men are personally interested, by education and association, in perpetuating systems of education based on the fruits of the former civilization. Another large body of men, now on the stage, and increasing in numbers, think it strange if Christian civilization cannot afford, in the study of free governments, of the broad political economy of the present, of the history, oratory, letters, and noble deeds, and the sciences of modern times, at least as good means of mental development as pagan civilization can, brooded over, as it was, by a crew of disreputable divinities. They claim that it can afford as good or better means. While, therefore, they respect all that is good in the achievements of the past, and would have the knowledge of them, and the culture based upon them, perpetuated so far as is useful in guiding and moulding the present, they believe that systems of education, based upon the two civilizations respectively, are best kept separate; and that, accordingly, it is a mistake to attempt to engraft schools of professional training in modern scientific pursuits upon classical colleges, as is done in several places in this country. 
Hardly anything, perhaps, could more effectually defeat the very desirable end of securing graduates of a previous general or collegiate course, as students in such professional schools; since there is so great a want of adaptation in a classical course, as a system of preparatory general aulture, for the prafessianal study of modern science.

The last idea surggests ane more which we must mention. The idea of a grand all-embracing unity besets and sways many minds. We confess to having once sympathized, more than now, with the idea of an encyclopædic institution, in which everything under the heavens should be taught; and this in behalf of a love for a visible unity. But there can be material unity - that is, essential unity of spirit, purpase, and effort, without formal unity-i.e., uniformity of methods, and concentration of men and means into a single institution. But, nevertheless, formal unity of some kind is desirable, and it can be abundantly had by the simple expedient, so harmonious with the usages of the times in other departments of life, of mutual fraternal recognition among all higher institutions, through the agency of local or national associations of their instructors, Such an association, embracing college, and professional school, and academy professors and teachers, already exists in New York State. Similar ones might be formed in other sections, or for the nation at large.

(To be continued)

\section{ffrunklin}

Procoedings of the Btated Yonthly Meeting, January, 16th, 1869.

The meeting was called to order with the President, Mr. J. Vaughan Merrick, in the Chair.

The minutes of the last meeting were read and approved. '

The Actuary submitted the minutes of the Board of Managers, and reported the donations received at their stated meeting held January 13th, inst.: from the Zoological Society, the Royal Astro. nomical Society, the Royal Institution, and the Society of Arts, London, and the Association for the Prevention of Steam Boiler 